\title{
Entrevista Dra. Sibel Erduran
}

\author{
Heslley Machado Silva'
}

'Centro Universitário de Formiga (UNIFOR/MG)

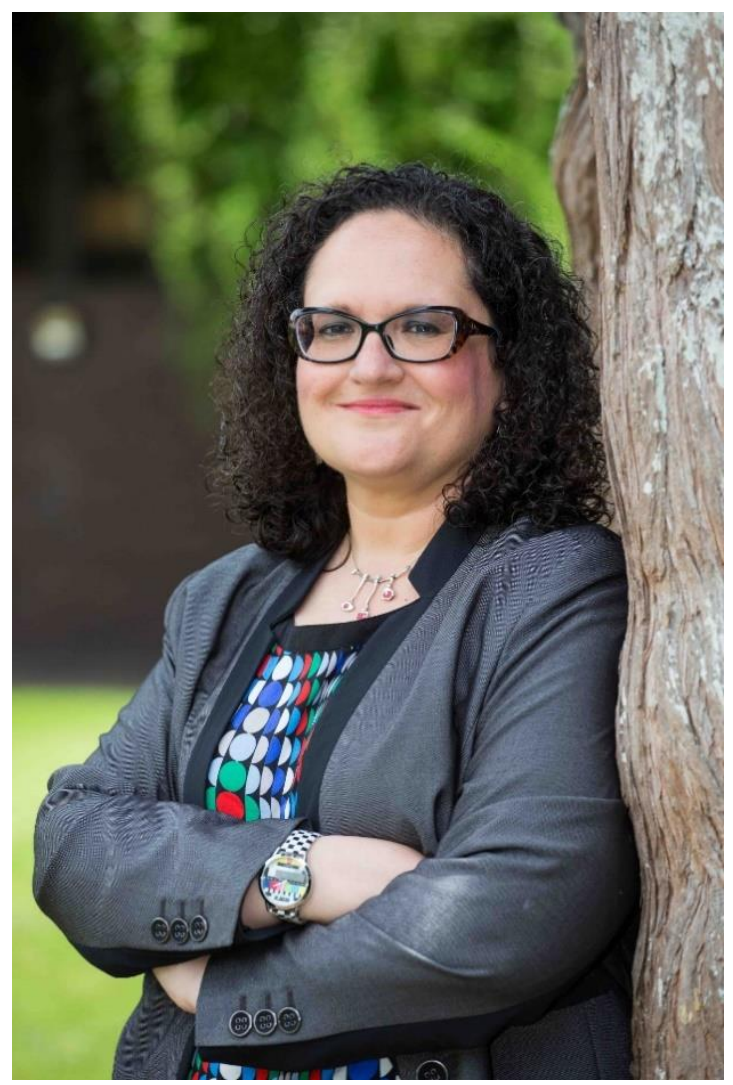

Sibel Erduran é Professora de Educação

Cientifica e Diretora de Pesquisa. Antes de sua

nomeação em Oxford, ela foi Presidente da STEM

Education na Universidade de Limerick, Irlanda,

onde foi Diretora da EPI-STEM, Centro Nacional

de Educação STEM

Ela ocupou o cargo de Professora Titular na Universidade Nacional Normal de Taiwan, Taiwan financiada pelo Taiwan Global Networking Talent Project; bem como de Professora Visitante na Universidade Kristianstad, Suécia, e na Universidade Bogazici, Turquia.

Ela é a Editora Chefe da revista Science \& Education, e editora do International Journal of Science Education. Ela é a Presidente da Associação Européia de Pesquisa em Educação Científica e Professora ll da Universidade de Oslo, Noruega. Anteriormente ela trabalhou na Universidade de Pittsburgh, EUA; King's College, Universidade de Londres; e Universidade de Bristol, Reino Unido. Ela foi professora de ciências do ensino médio e de química do ensino médio em uma escola com currículo britânico no norte de Chipre.

Ela completou sua educação superior nos EUA nas Universidades Vanderbilt (Doutorado em Educação científica \& Filosofia), Cornell (Mestrado em Química alimentar) e Northwestern (Bioquímica). Seus interesses de pesquisa se concentram nas aplicações na educação científica das perspectivas epistêmicas na ciência em geral e na química em particular. Seu trabalho em argumentação recebeu prêmios da NARST e EASE. 
Ela tem recebido financiamento do Programa Fulbright, Spencer Foundation, Gatsby Foundation, Nuffield Foundation, TDA, Wellcome Trust, EU Marie Curie Brain Circulation Scheme, Science Foundation Ireland, Irish Research Council, BERA e NCCA entre outros. Atualmente ela é a líder de dois projetos, financiados pelo Wellcome Trust e pela Templeton World Charity Foundation.

É um privilégio termos alguém como Sibel Erduran, com esse lastro acadêmico para nossa seção de entrevista, então vamos aproveitar a oportunidade e usufruir um pouco dos seus saberes e experiência.

1. Indo direto ao ponto, você é editora de duas das revistas mais importantes do mundo do campo da educação, quais os principais problemas encontrados nos artigos que você recebe? Que dicas você daria para os nossos leitores que querem publicar nessas revistas?

Dr. Sibel: Em um nível muito básico, vejo que muitas pessoas submetem artigos sem terem examinado a revista de perto. Por exemplo, na Science \& Education, há um foco muito particular na História, Filosofia e Sociologia da Ciência, e da Educação Científica. Algumas pessoas submetem artigos sem qualquer fundamentação do quadro teórico sobre esse tema. Assumem que a revista aceitaria qualquer tipo de artigo de educação científica. Por isso, a minha primeira sugestão é examinar bem a revista. Leia alguns exemplos de artigos e descubra o que é aceitável, dado que estes são artigos publicados. Outro problema é que, por vezes, as pessoas replicam estudos em diferentes países e pensam que essa replicação será inovação. Uma publicação deve ser uma contribuição original, por isso, a menos que o contexto do novo país possa introduzir algo novo, não é propriamente um artigo publicável, mesmo que esteja bem escrito com abordagens teóricas e metodológicas sólidas.

2. Você teve uma trajetória profissional e acadêmica singular, tendo trabalhado em diversas regiões do mundo em diversas Universidades, com realidades distintas. Nos fale um 
pouco sobre essa experiência, como ela pode ser rica, as dificuldades e como alcançar esse privilégio.

Dra. Sibel: Tive de fato muita sorte em ter feito toda a minha educação superior nos EUA, e já trabalhei em 3 universidades britânicas diferentes. Também trabalhei na Irlanda e tive cátedras visitantes na Suécia, Turquia, Taiwan e Noruega. Essas experiências têm enriquecido a minha compreensão da educação científica em diferentes contextos. Algumas das minhas outras experiências, tais como as de países do continente africano, abriram-me os olhos para os nossos pressupostos sobre o que a educação poderia ou deveria ser. Assim, acima de tudo, essas experiências levaram-me a apreciar a importância das hipóteses na investigação.

\section{Sua posição como diretora de} pesquisa em educação e ciência da Universidade de Oxford, considerada por muitos como a melhor Universidade do mundo, Ihe permite uma visão privilegiada sobre a educação no planeta. Quais são, na sua opinião, os principais desafios para a educação mundial? Quais os possíveis caminhos para superá-los?

Dra. Sibel: Neste momento, os desafios importantes no mundo incluem questões de justiça social, equidade na representação e resolução eficaz de problemas. O próprio planeta enfrenta problemas significativos devido às alterações climáticas e enfrentamos uma grande emergência planetária se não agirmos com rapidez suficiente. Para grandes problemas como as alterações climáticas, precisamos de encontrar uma convergência para a vontade política e o consenso científico. De acordo com esse objetivo, precisamos de educar o público, bem como os estudantes das escolas e universidades, sobre a razão pela qual consideramos que a mudança climática é real. Muitas pessoas são doutrinadas ao conhecimento científico, sem que se perceba como e porque é que tomamos certas alegações como verdadeiras. Há uma grande componente da educação que precisa de 
fomentar nos cidadãos a

capacidade de raciocínio baseado em provas. No entanto, o ensino sobre racionalidade e evidência não alcançará necessariamente a resolução de problemas. Muitos problemas também têm valores, moralidade e identidades embutidos neles. Precisamos de aprender a fomentar um certo tipo de tolerância que assegure compaixão, empatia e comunicação entre as pessoas.

4. Um dos grandes problemas que vivenciamos no Brasil, e em muitas partes do mundo, é a falta de financiamento para pesquisas. Você teve vários projetos financiados por grandes agências de fomento de várias regiões do mundo. Nos dê dicas para termos acesso a esse tipo de recursos.

Dra. Sibel: $\bigcirc$ financiamento da investigação é um problema significativo em muitas partes do mundo, incluindo o Reino Unido. As fontes são escassas e, por vezes, também podem ser cortadas no meio da duração do projeto, como temos experimentado em tempos recentes no Reino Unido. Mesmo assim, há certos fundos disponíveis em nível nacional e internacional. Muito disso exige que se faça alguma investigação sobre os financiadores. Por exemplo, eu prestaria atenção a quais os financiadores que os investigadores citam nos seus trabalhos. A elegibilidade pode ser um problema em alguns casos, mas vale a pena acompanhar as informações dos financiadores por meio do trabalho de outros colegas. Às vezes, as chamadas são feitas por meio de listas de distribuição profissional por e-mail.

5. Falando sobre $\circ$ seu departamento em Oxford e sua atuação como pesquisadora, qual $\circ$ perfil de um estudante desejado para ser seu orientando no mestrado ou doutorado? Quais as habilidades que você mais valoriza em um pesquisador?

Dra. Sibel: Gosto que os meus alunos tenham um sentido de iniciativa em que possam prosseguir e descobrir informações sem eu estar sempre a dizer-lhes para 0 
fazerem. Isso inclui trazer novas ideias para a própria mesa. Podemos negociar essas ideias, mas é importante que os estudantes sejam pensadores independentes.

Também valorizo quando os estudantes podem ser críticos e não aceitam tudo o que leem. Ser crítico com evidências e justificações é importante para o trabalho de mestrado e doutoramento. Descobri que os mais bemsucedidos dos meus alunos também não se têm coibido em fazer uma série de coisas, mesmo quando não Ihes foi pedido que o fizessem. Por exemplo, ajudar na organização de um evento, receber colegas e assim por diante. Há um conjunto mais amplo de competências que são desenvolvidas por meio do envolvimento em diferentes atividades que acabam por contribuir para

desenvolvimento do investigador para além do simples conhecimento de conceitos e métodos.

\section{Qual a sua percepção sobre a pesquisa e a educação no Brasil? Tem interesse em alguma}

questão própria do Brasil e da América Latina?

Dra. Sibel: Tive alguns colaboradores do Brasil e posso dizer genuinamente que tenho gostado muito de trabalhar com eles. Há um certo nível de curiosidade intelectual no Brasil que me agrada muito. Penso que muitas pessoas no Brasil podem também relacionar-se com 0 meu trabalho, pois vejo que tendem a utilizar a minha investigação. Gostaria de poder ler e compreender português porque estou ciente de que existem muitos pontos de vista de publicação em que muitos conhecimentos são desenvolvidos e partilhados. Estou certamente interessada na investigação educacional no Brasil e, mais amplamente, na América Latina.

7. Quais tópicos você considera como "temas quentes" para os próximos anos para a pesquisa na área da educação? Por quê?

Dra. Sibel: Dado o contexto pandêmico, bem como as questões tais como as injustiças sociais que a pandemia expôs ainda mais, haverá muito esforço 
para se fazer um olhar holístico sobre a educação, a fim de assegurar que podemos ter abordagens sistemáticas para resolver problemas. Precisamos de levar a sério as colaborações interdisciplinares

multidisciplinares porque muitos problemas requerem muitas perspectivas. O Covid-19 é um desses exemplos. Não basta centrarmo-nos apenas na imunologia em torno da pandemia. Já vimos que a política, a economia, os regulamentos de saúde pública, etc., precisam de ser considerados

concomitantemente para resolver o problema.

\section{No início da sua carreira, você} foi professora de Ensino Médio, a partir dessa experiência profissional nos fale sobre como vale a pena a carreira de professor atualmente.

Dra. Sibel: $O$ ensino tem sido sempre um aspecto importante da minha vida. O meu pai e o meu avô foram professores. Cresci numa casa onde a profissão de professor era altamente respeitada. $\mathrm{Na}$ verdade, provavelmente todas as conversas na nossa casa foram experiências pedagógicas para mim. Assim, ensinar é uma grande parte da minha própria identidade pessoal. Para além disso, ser professora de química secundária e de ciências do ensino médio dotou-me de alguma compreensão dos alunos. Tenho visto que as crianças também querem ser respeitadas. Elas respondem bem se as levarmos a sério, e não as considerarmos como limitadas ou atrevidas. Cada aluno tem potencial para aprender alguma coisa e é nosso trabalho como educadores expor e construir sobre esse potencial. Como professor, sempre pensei que era minha própria responsabilidade tornar as lições interessantes para os meus alunos. Se eles não estavam e estivessem fora de serviço, isso significava que eu não estava a fazer o suficiente ou a fazer a lição de uma forma que seria envolvente para eles. Não acredito em concentrar-me na gestão do comportamento neste sentido. Penso que todas as crianças podem aprender a comportar-se, podemos ensiná- 
las, por meio do seu interesse e empenho cognitivo e social. As crianças precisam de um propósito na sua aprendizagem e, como professor, esforcei-me por Ihes dar tal propósito. Isso é verdade para o ensino hoje e será sempre verdade para qualquer professor no futuro. Os professores são pilares da sociedade. Não podemos ter nenhum profissional sem bons professores a desenvolvê-los.

9. O mundo vivencia uma intensa difusão Fake News e teorias conspiratórias científicas, problema especialmente crítico no Brasil, como você percebe essa questão? Como você sugere enfrentá-la?

Dra. Sibel: Precisamos ensinar às pessoas capacidades de pensamento crítico, a capacidade de avaliar evidências e reivindicações. Mais importante ainda, porém, precisamos de ensinar as pessoas a respeitar a evidência, porque se não respeitarem a evidência, então não tenho a certeza de quão eficaz será esperar que elas utilizem a evidência. Podemos fornecer alguns exemplos que ilustram por que razão a evidência é importante. Por vezes, a personalização de situações pode ajudar. Por exemplo, se fosse assaltado, quereria que o ladrão fosse apanhado? Quereria que as provas fossem recolhidas e utilizadas de uma forma que identificasse o ladrão? Isso é verdade nos dias que correm nas compras online.

10. Para finalizar, dê-nos uma palavra de incentivo para nossos leitores que pensam em se tornar pesquisadores a partir da sua carreira muito bem-sucedida.

Dra. Sibel: Sugiro que os leitores sigam o que quer que lhes interesse. Sigam as suas paixões e não se contentem com menos. Descubra no que é que VOCÊ está interessado, não no que os outros pensam que você está ou deveria estar interessado. Se der os pequenos passos, todas as decisões para coisas que gosta de fazer profissionalmente em termos de investigação, então acabará por reunir a amplitude de experiências que 0 irão instalar num contexto profissional que funciona para si. 